\section{PRESERVING YOUR COMPRESSOR'S LIFE}

Just as batteries should be replaced annually on your smoke alarm, so too should the filter on your compressor. With Durr Dental compressors, the process is just as easy as changing batteries. Simply log on to www.duerr.de/filter and enter the code number for your compressor and click 'Find Filter'. The model you require will be displayed immediately. Replacing the filter annually will preserve the service life of your compressor.

Durr Dental compressors have a good track record for longevity and efficiency. This is ensured by their antibacterial tank coating, designed for permanent operation, and their novel use of dry air technology. All Durr compressors carry a three year warranty. To find out more, call 01536526740.

\title{
FASTER BRISTLE SPEED, GREATER PLAQUE REMOVAL
}

At this year's BDTA Dental Showcase, delegates had the opportunity to discover all the latest innovations from Waterpik International.

The team were on hand to demonstrate the Waterpik Complete Care system, consisting of the Waterpik Water Flosser and Sensonic Professional Plus Sonic Toothbrush.

Clinically proven to remove up to $99.9 \%$ of plaque biofilm from treated areas, delegates found that the water flosser complements the sonic toothbrush perfectly, as the latter boasts 25\% faster bristle speed than other comparative products and up to $29 \%$ better plaque removal.

The Waterpik team also launched the newly refined WP-120 Ultra Water Flosser, which now comes with a new two-pin plug for easy charging from a standard UK shaver socket. Already the number one recommended water flosser by US dentists, it is now widely available to UK professionals and patients as well.

For more information on Waterpik Water Flossers speak to your wholesaler or visit www.waterpik.co.uk. Waterpik products are widely available in Boots stores and selected Lloyds Pharmacies.

\section{EXCELLENT SEALS FOR AUTOCLAVES}

Autoclaves sterilise equipment with high pressure saturated steam at temperatures of $121^{\circ} \mathrm{C}$ or more. In between loads, autoclaves are subject to continuous cleaning cycles at high pressure/ temperature steam conditions.

It is of paramount importance

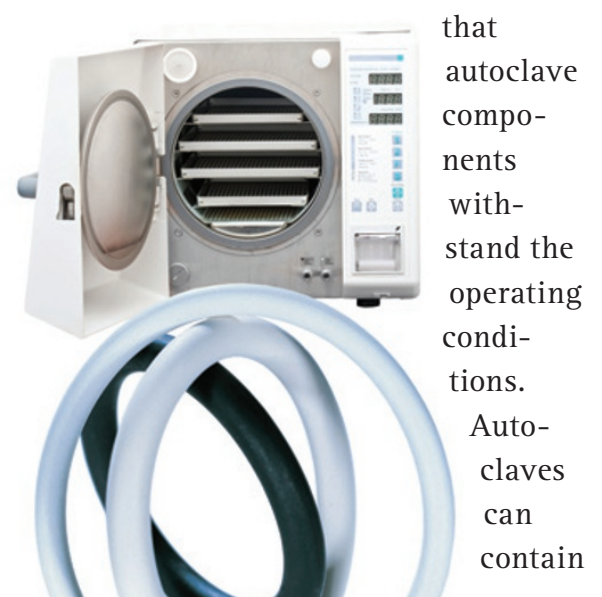

in excess of 200 seals that need to maintain their performance in hot pressurised saturated steam, as well as also being FDA and USP Class VI compliant.

The DuPont Kalrez 6230 perfluoroelastomer (FFKM) seals have been developed to meet such unique requirements while providing excellent sealing qualities to comply with modern pharmaceutical processes. These products are available from the UK authorised distributor Dichtomatik Ltd, and reduce extractables to trace levels while providing excellent steam cycling resistance up to $260^{\circ} \mathrm{C}$. Where in situ tests have been conducted with saturated steam at 4 bar pressure and $140{ }^{\circ} \mathrm{C}$ temperature, the Kalrez 6230 seal parts performed well over a four month test duration of eight hours per day and five days per week. At the end of the test period, the seals exhibited few or no cracks and only minor compression set when compared to competitive perfluoroelastomer (FFKM and FKM) materials.

For more information telephone 01332524401 or visit www.dichtomatik-kalrez.co.uk.

\section{AN AESTHETICALLY ARRESTING SONIC TOOTHBRUSH}

Following the success of the original award-winning Sonicare DiamondClean, Philips launched a new Sonicare DiamondClean Black at BDTA Dental Showcase last month. The first black toothbrush in the range is aesthetically arresting and takes sonic tooth brushing to a new level of designer chic.

DiamondClean Black is also clinically proven to remove up to $100 \%$ of plaque from hard to reach places and to improve gum health in only two weeks. It is also clinically proven to whiten teeth in one week, and its gentle technology actually protects against abrasion and gum recession to help reduce sensitivity.

To encourage greater compliance, the new Sonicare Diamond Clean Black incorporates a raft of technological wizardry to encourage patients to clean their whole mouth effectively. It has five bespoke brushing modes: clean, white, polish, gum care and sensitive, which allow them to tailor their brushing according to their needs, as well as their dental professional's advice. Its matt brush head sports a new diamond-cut tuft formation meaning that it has $44 \%$ more bristles than Philips' standard sized ProResults brush heads.

DiamondClean Black's chrome base has a unique charging glass with the latest in conduction technology to charge the toothbrush as it rests in the glass. It also comes with a revolutionary USB travel case which can be plugged into a laptop computer - although the brush holds three weeks of charge. 